Paivio, A. Mental imagery in associative learning and memory. Psy chological Review, 1969, 76, 241-263.

Paivio, A. Imagery and verbal processes. New York: Holt, Rinehart, \& Winston, 1971

Paivio, A., Yuille, J. C., \& Madigan, S. Concreteness, imagery, and meaningfulness values for 925 nous. Journal of Experimental Psychology Monograph Supplement, 1968, 76, (1, Pt. 2).

Robbins, D., Bray, J. F., Irvin, J. R., \& Wise, P. R. Memorial strategy and imagery: An interaction between instructions and rated imagery. Journal of Experimental Psychology, in press. Schnorr, J. A., \& Atkinson, R. C. Repetition versus imagery instructions in the short-term and long-term retention of paired-associates. Psychonomic Science, 1969, 15, 183-184.
Thorndike, E. L., \& Lorge, J. The teacher's wordbook of 30,000 words. New York: Teachers College, Columbia University, 1944.

Tulving, E., McNulty, J. A., \& Ozier, M. Vividness of words and learning to learn in free-recall learning. Canadian Journal of Psychology, 1965, 19, 242-252.

Winnick, W. A., \& Kressel, K. Tachistoscopic recognition thresholds, paired-associate learning and immediate recall as a function of abstractness-concreteness and word frequency. Journal of Experim ental Psychology, 1965, 70, 163-168.

\title{
High-speed memory scan as a retention interval activity in short-term memory*
}

\author{
DAVID S. GORFEIN \\ New College, Sarasota, Florida 33578
}

\begin{abstract}
A Sternberg high-speed memory scan task was used as a retention interval activity in a standard Brown-Peterson paradigm. Two levels of Sternberg search set, one or five items, were employed to see if the differential memory load produced by the different size search sets resulted in differential recall in the Brown-Peterson task. A comparison was made to a control condition in which $\mathrm{S}$ was required to shadow digits during the retention interval. No differential effect on recall of memory load was found when the Sternberg tasks were compared across three different retention intervals. Very little forgetting was produced by the Sternberg tasks as compared to the digit shadowing condition. Results are discussed in terms of the need for verbal activity to prevent rehearsal in short-term memory.
\end{abstract}

Researchers in memory have frequently adopted the technique of varying the retention interval activity in an attempt to explicate the storage and rehearsal process. In short-term memory (STM) utilizing the Brown-Peterson paradigm (Brown, 1958; Peterson \& Peterson, 1959), dependence of recall on the retention interval activity has been well demonstrated. Posner and Rossman (1965) have varied information processing in the retention interval while Loess and McBurney (1965) have also shown effects of the difficulty of the retention interval task. Such manipulations, however, provide no theoretical basis for understanding the amount of interference obtained. There is no basis for determining how the interfering activity interacts with items in storage. Many of the modern conceptions of information processing, e.g., Atkinson and Shiffrin (1968), postulate a limited capacity working memory which can only process items for long-term storage insofar as the capacity of working memory (generally shown to be in the range from 1 to 5 items) is not exceeded. We have no way of determining whether such variables as amount of information reduced (Posner, 1964) influences time alone (S may take longer to do a more difficult information processing task), working memory capacity (it may take more capacity to do the more difficult tasks), or some combination of time and capacity. The

*This research was supported by Public Health Service Grant MH 19799-01. problem is essentially that we have no direct way of measuring the amount of working memory capacity utilized for the tasks traditionally used as retention interval activities.

Sternberg $(1966,1967)$ has presented evidence that these parameters (memory load and processing time) may be specifiable for a type of memory search task. In this task $\mathrm{S}$ first learns a set of digits (the set size can be varied from task to task). S's retention of the digit is tested by a probe recognition task in which the $S$ in instructed to press one of two keys to indicate that, yes, the probe was a member of the to-be-remembered set, or, no, the probe item was not a member of the to-be-remembered set. Reaction time data is recorded. By analysis of the reaction time data, Sternberg shows that this paradigm is comparable to an analogous paradigm in short-term memory where a new to-be-remembered set is presented just prior to each probe. The data show an exhaustive search of the to-be-remembered set. Sternberg argues cogently that this indicates that the search set is transferred to working memory and then searched exhaustively (his argument is based on the identical slope of reaction time as a function of the size of search set to that in the short-term high-speed scan paradigm but an increase in intercept in the long-term paradigm). The Sternberg paradigm therefore provides the desirable features of allowing us to measure directly the time taken by the task and the amount of capacity occupied by the task 
(the size of the search set). Further, Sternberg has shown that the increment in reaction time produced by any one item in the search set is on the order of $35 \mathrm{msec}$. This produces the advantage for our research that large changes in working memory capacity occupies (a ratio of 5 to 1 as we vary search set size from 1 to 5 items) are associated with very small changes in total processing time for two tasks (an expected range of $140 \mathrm{msec}$ of a total time of $600 \mathrm{msec}$ approximately).

\section{METHOD}

Subjects

Forty-two New College students were paid to participate in this study.

\begin{abstract}
Design
The experiment employing the Brown-Peterson short-term memory paradigm can be basically subdivided into two parts. One part, the main experimental conditions, consisted of 36 (Ss) by 2 (types of to-be-remembered material) by 2 (size of Sternberg set used as a retention interval activity) by 3 (length of retention interval) by 6 (trials within a block of material) design. A control condition was run using a standard number shadowing task as the retention interval activity and only one of the three retention intervals utilized in the main experiment. Each of the $36 \mathrm{Ss}$ in the main experiment were tested on 72 trials in the Brown-Peterson task. Two sessions of 36 trials were utilized. In one session, the retention interval was filled with a self-paced Sternberg high-speed long-term memory search with a single item in the to-be-remembered set. In the other session, the Sternberg set was 5 items in length. Prior to each session $\mathrm{S}$ was well practiced in the Sternberg task alone under self-paced conditions. Half of the Ss performed the 1-item search first and half the 5-item search. The 36 trials in a session were composed of six blocks of six trials. Alternating blocks of CCCs and word triads were the TBRIS. Items within a block were completely counterbalanced across Ss and the first block in each session was similarly counterbalanced. Within each session, three different retention intervals were used equally of ten for both types of material with the order of retention intervals also suitably counterbalanced. The three retention intervals employed were 2 , 5 , or $11 \mathrm{sec}$. By alternating the blocks of materials, we in effect achieved a condition that would produce release from proactive inhibition (PI) and therefore allow us to expect a build-up effect of PI across the six trials of a block.

As mentioned above, the control involved testing only six Ss, using the same to-be-remembered material. In the case of the control condition, the retention interval was filled with digit shadowing with the digits being presented by a Binaview display at a rate of $4 / \mathrm{sec}$. A single retention interval $(11 \mathrm{sec})$ was employed in this condition. The experimental session was divided into two sessions just as for the experimental conditions, with time between sessions kept equal to that in the experimental conditions.
\end{abstract}

\section{Materials}

The to-be-remembered items (TBRIs) were unrelated three-word triads consisting of four letter monosyllabic English nouns and consonant trigrams of $33 \%$ association value (Witmer, 1935). Trigrams were so arranged that within a block of six trials the same letter did not occur within the same within trigram serial position.

\section{Sternberg Task}

The Sternberg Memory Scan Test had two conditions, either a 1-item Sternberg search set or a 5-item search. In either case, the $\mathrm{S}$ was well practiced on the Sternberg task alone prior to it being used as a retention interval activity. The task set consisted of an appropriate number of digits selected at random. Correct targets for the Sternberg search occurred randomly on $50 \%$ of the trials and the Ss (pressing a yes or no key) initiated the next trial which was presented immediately by a Binaview display. Thus, the Sternberg task was completely self paced. The Sternberg performance was recorded by an on-line tape punch which measured reaction time in milliseconds from onset of display to keypress.

\section{STM Procedures}

Items were presented by a Kodak Carousel projector controlled by Hunter timers. Ss were tested individually in a sound attenuated cubicle. Brown-Peterson trials were a constant $25.6 \mathrm{sec}$ in duration. Ss were presented with a $1.5-\mathrm{sec}$ ready signal, the TBRI for $1.1 \mathrm{sec}$, the retention interval for 2,5 , or $11 \mathrm{sec}$ as described above, during which a yellow slide appeared on the screen, and the Binaview display was operating, five asterisks to signal recall for $10 \mathrm{sec}$, and a rest period so adjusted that the combined total time for the retention and the rest periods was $13 \mathrm{sec}$. Thus, when the retention period was $2 \mathrm{sec}$, the rest period was $11 \mathrm{sec}$. When retention was 5 , rest was $8 \mathrm{sec}$, and retention periods of $11 \mathrm{sec}$ had a rest of $2 \mathrm{sec}$. It has been suggested (Scheirer \& Voss, 1969) that the crucial variable in determining PI build-up is the interval between the presentation of one TBRI and the next TBRI. Hence, we felt it was important to keep total time on a trial constant.

\section{RESULTS}

Items were scored for correct item in correct within-trial serial position. An analysis of variance was performed among the Sternberg conditions alone, with the analysis being a 2 (Sternberg treatments) by 2 (materials) by 3 (retention intervals) by 6 (serial positions within a block of trials) by 36 (Ss) design. Figure 1 presents the data collapsed across the material for clarity since there were no interactions that reached statistical significance. For the purpose of this study the most notable finding is that the Sternberg task has no differential effect on retention, $F(1,35)<1$. None of the interactions involving the Sternberg treatment were significant. Significant effects were obtained for the retention intervals, $F(2,70)=10.87, p<.01$. Effect of serial position within a block was significant, $F(5,175)=$ $3.14, p<.01$, as were the effects of materials, $F(1,35)=$ $123.45, p<.001$. This last effect results from a large difference between the materials with CCCs averaging 2.61 out of a possible 3 in ordered item recall as compared to 2.09 for the word triads.

Examination of the serial position curves across the three retention intervals for the Sternberg condition, however, shows that all of these functions are relatively flat with very little PI build-up. This is particularly striking when compared with the control condition in which the Ss shadow digits throughout. An analysis of variance comparing the $11-\mathrm{sec}$ retention interval Sternberg conditions with the control condition shows a highly significant effect of conditions. Using a pseudo-four-way analysis (treating Ss in the Sternberg condition as consisting of six pseudo-Ss in each condition) the effect of experimental treatment is $F(2,15)=11.22, p<.01$. 
Table 1

Effect of Conditions on High-Speed Scan

\begin{tabular}{|c|c|c|c|c|c|c|}
\hline \multirow{3}{*}{$\begin{array}{c}\text { Set } \\
\text { Size } \\
\end{array}$} & \multicolumn{4}{|c|}{ Effect on Reaction Time in Msec } & & \\
\hline & \multicolumn{2}{|c|}{ Practice } & \multicolumn{2}{|c|}{ Test } & \multicolumn{2}{|c|}{ Effect on Percent Error } \\
\hline & Corr Det & Corr Rej & Corr Det & Corr Rej & Practice & Test \\
\hline $\begin{array}{l}1 \\
5\end{array}$ & $\begin{array}{l}541.87 \\
583.62\end{array}$ & $\begin{array}{l}543.03 \\
616.04\end{array}$ & $\begin{array}{l}550.75 \\
586.38\end{array}$ & $\begin{array}{l}560.2 \\
590.48\end{array}$ & $\begin{array}{l}6.95 \\
7.71\end{array}$ & $\begin{array}{l}13.64 \\
14.36\end{array}$ \\
\hline
\end{tabular}

Table 1 shows the comparison of the Sternberg tasks as a retention interval activity to the conditions where $\mathrm{S}$ was practicing the Sternberg tasks alone. The practice data represents performance on the last 100 practice trials. While there is an increase in errors, there is very little other effect of Ss' efforts to remember the to-be-remembered item in the Brown-Peterson paradigm on the Sternberg task.

\section{DISCUSSION}

The most striking finding in this study is the failure of the two Sternberg tasks to produce differential forgetting despite what we believe to be a large difference in memory load required by
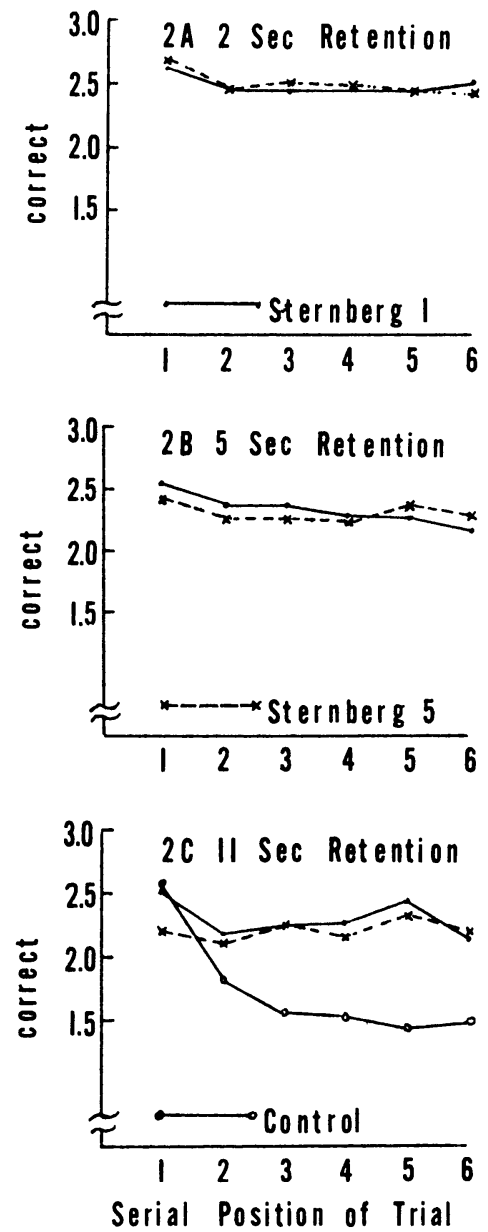

Fig. 1. Within-block serial position curves as a function of length of retention interval and retention interval activity. the two tasks. One possible explanation would be that the $S$ is not performing the Sternberg task adequately and therefore leaving himself large amounts of time to rehearse. As was shown in Table 1, however, the only major change was in the number of errors, which did increase when the Sternberg task was a retention interval activity. It is doubtful, however, that this accounts for the effect since the reaction time in the Sternberg task did show a sizeable differential memory load of the two sizes of search sets. An alternative explanation that is consistent with the literature is that rehearsal is not prevented in STM tasks (even though $S$ was instructed not to rehearse) by nonverbal tasks, i.e., tasks that do not require the $S$ to vocalize during the retention interval (Reitman, 1971; Shiffrin, 1973). A recent study (Watkins, Watkins, Craik, \& Mazuryk, 1973) purports to show a significant PI build-up in a nonverbal distraction task, that of shadowing tones by pushing appropriate keys. However, they report "in addition, Ss were instructed to hum each note as they pressed the key [Watkins et al, 1973, p. 297]." Therefore, it is not clear that their task was really a nonverbal one.

It should be noted that although some studies in the literature, e.g., Murdock (1961), have failed to find a differential effect on performance of word triads as compared to consonant trigrams, we find a very large and significant effect of materials. Our Ss report that it is much easier to convert a consonant trigram to a single chunk than it is for a word triad.

\section{REFERENCES}

Atkinson, R. C., \& Shiffrin, R. M. Human memory: A proposed system and its control processes. In K. W. Spence and J. T. Spence (Eds.), Advances in the psychology of learning and motivation theory. Vol. II. New York: Academic Press, 1968.

Brown, J. A. Some tests of the decay theory of immediate memory. Quarterly Journal of Experimental Psychology, $1958,10,12-21$.

Loess, H., \& McBurney, J. Short-term memory and retention interval activity. Proceedings of the 73rd Annual Convention of the APA, 1965, 85-86.

Murdock, B. B. The retention of individual items. Journal of Experimental Psychology, 1961, 62, 618-625.

Peterson, L. R., \& Peterson, M. J. Short-term retention of individual verbal items. Journal of Experimental Psychology, $1959,58,193-198$.

Posner, $M$. I. Information reduction in the analysis of sequential tasks. Psychological Review, 1964, 71, 491-504.

Posner, M. I., \& Rossman, E. Effect of size and location of informational transforms upon short-term retention. Journal of Experimental Psychology, 1965, 70, 496-505.

Reitman, J. S. Mechanisms of forgetting in short-term memory Cognitive Psychology, 1971, 2, 185-195.

Scheirer, C. J., Voss, J. F. Reminiscence in short-term memory. Journal of Experimental Psychology, 1969, 80, 262-270.

Shiffrin, R. M. Information persistence in short-term memory. Journal of Experimental Psychology, 1973, 100, 39-49.

Sternberg, S. High speed scanning in human memory. Science, $1966,153,652-654$.

Sternberg, S. Two operations in character recognition: Some evidence from reaction-time measurements. Perception \& Psychophysics, 1967, 2, 45-43.

Watkins, M. J., Watkins, O. C., Craik, F. I. M., \& Mazuryk, G. Effect of non-verbal distraction on short-term storage. Journal of Experimental Psychology, 1973, 101, 296-300.

Witmer, L. P. The association value of three-place consonant syllables. Journal of Genetic Psychology, 1935, 47, 337-360.

(Received for publication January 18, 1974.) 